\title{
Pesquisa de anticorpos contra o sarampo em crianças infectadas pelo HIV, após a imunização básica
}

\author{
Search of antimeasles antibodies in HIV-infected children after basic immunization
}

\author{
Claudia R. Lindgren-Alves ${ }^{1}$, Lincoln M.S. Freire ${ }^{2}$, Rodrigo C. Oliveira ${ }^{3}$, Henrique L. Guerra ${ }^{4}$, \\ Edson E. Da-Silva ${ }^{5}$, Marilda M. Siqueira ${ }^{6}$, Isabela Morgan Horta ${ }^{7}$, Claudia C. Queiroz ${ }^{8}$
}

\section{Resumo}

Objetivo: verificar a presença de anticorpos contra o sarampo em crianças com infecção perinatal pelo HIV e devidamente imunizadas.

Métodos: estudo de coorte retrospectivo realizado em Belo Horizonte, entre 1995 e 1996. Foram incluídas 21 crianças com infecção perinatal pelo HIV e 29 crianças imunocompetentes nãoinfectadas. Informações acerca da vacina contra o sarampo foram obtidas do cartão de imunizações dos pacientes. A pesquisa de anticorpos contra o sarampo foi realizada pelos testes de neutralização por redução de placa e dosagem de IgM pela técnica de ELISA. Adotou-se nível de significância de 5\% em todas as análises estatísticas realizadas.

Resultados: a mediana de idade dos pacientes infectados pelo HIV foi de 44,5 meses, e das crianças não-infectadas, de 62,0 meses $(\mathrm{p}=0,64)$. Os grupos receberam em média 2 doses da vacina contra o sarampo. Todos os pacientes soronegativos para o HIV apresentaram títulos de anticorpos contra o sarampo superiores a $50 \mathrm{mUI} / \mathrm{ml}$, enquanto $57,1 \%$ das crianças infectadas apresentaram títulos acima deste valor $(\mathrm{p}=0,0001)$. O título geométrico médio de anticorpos neutralizantes (GMT) foi significativamente menor no grupo de crianças com infecção pelo $\mathrm{HIV}(433,5 \mathrm{mUI} / \mathrm{ml})$ do que no grupo de não-infectados( $1668,1 \mathrm{mUI} / \mathrm{ml}), \mathrm{p}=0,001$. Todos os pacientes dos dois grupos foram negativos para a pesquisa de $\operatorname{IgM}$ contra $\mathrm{o}$ sarampo.

Conclusão: as crianças infectadas pelo HIV apresentaram menor soroprevalência de anticorpos contra o sarampo após a imunização do que as crianças não-infectadas. Esses resultados alertam para o risco potencial de aquisição do vírus do sarampo, e apontam a necessidade de avaliar alternativas para a imunização das crianças infectadas pelo HIV, no sentido de maximizar a proteção contra o sarampo nesse grupo de pacientes.

J Pediatr (Rio J) 2001; 77 (6): 496-502: vacina contra sarampo, infecção perinatal, soroprevalência de HIV.

\begin{abstract}
Objective: to determine the presence of antimeasles antibodies in children perinatally infected with HIV and properly immunized.

Methods: a retrospective cohort study conducted in Belo Horizonte by the Universidade Federal de Minas Gerais, between 1995 and 1996. Twenty one children perinatally infected with HIV and 29 immunocompetent noninfected children were included in the study. Information about measles vaccination was obtained from patients' immunization charts. The presence of neutralizing antibodies against the measles was determined by the plaque reduction neutralization test and IgM was measured by ELISA. The level of significance was set at 5\% in all the performed statistical analyses.

Results: median age was 44.5 months for HIV-infected patients and 62.0 months for noninfected children $(\mathrm{P}=0.64)$. Both groups received on average two doses of antimeasles vaccine. All HIVseronegative patients presented antimeasles antibody titers greater than $50 \mathrm{mIU} / \mathrm{ml}$, whereas $57.1 \%$ of infected children presented titers above this value $(\mathrm{P}=0.0001)$. The geometric mean titer of neutralizing antibodies was significantly lower in the group of HIV-infected children $(433.5 \mathrm{mIU} / \mathrm{ml})$ than in noninfected children $(1,668.1 \mathrm{mIU} /$ $\mathrm{ml}), \mathrm{P}=0.001$. All patients in both groups were negative for antimeasles $\operatorname{IgM}$.
\end{abstract}

Conclusion: in the present study, HIV-infected children showed a lower seroprevalence of antimeasles antibody after immunization than noninfected children. These results emphasize the risk of acquisition of measles virus and the need to evaluate alternatives to the vaccination of HIV-infected children in an attempt to maximize the protection against the measles in this group of patients.

J Pediatr (Rio J) 2001; 77 (6): 496-502: measles vaccine, perinatal infection, HIV seroprevalence.

1. Profa Assistente do Depto. de Pediatria da Faculdade de Medicina, Universidade Federal de Minas Gerais (UFMG), Mestre.

2. Prof. Adjunto do Depto. de Pediatria da Faculdade de Medicina - UFMG, Presidente da Sociedade Brasileira de Pediatria, Doutor.

3. Chefe do Laboratório de Imunologia Molecular e Celular do Centro de Pesquisa René Rachou-FIOCRUZ (MG), Doutor.

4. Pesquisador Titular do Laboratório de Epidemiologia e Antropologia do Centro de Pesquisa René Rachou-FIOCRUZ (MG), Mestre.

5. Pesquisador Titular - Laboratório de Enteroviroses da FIOCRUZ (RJ), Doutor.

6. Pesquisadora Titular - Laboratório de Vírus Respiratórios da FIOCRUZ (RJ), Doutora.

7. Residente da Fundação Hospitalar de Minas Gerais, Médica.

8. Pesquisadora do Laboratório de Imunologia Molecular e Celular do Centro de Pesquisa René Rachou-FIOCRUZ(MG), Doutora.

Artigo submetido em 15.01.01, aceito em 11.07.01. 


\section{Introdução}

A vacina contra o sarampo é composta por vírus vivos atenuados e, por esse motivo, contra-indicada para os pacientes imunodeprimidos, devido ao risco de replicação do vírus vacinal. No entanto, a gravidade do sarampo nas crianças infectadas pelo HIV fez com que essa vacina fosse rotineiramente indicada nesses pacientes. Segundo recomendações do Advisory Comitee in Immunization Practices (ACIP), a vacina de vírus vivos atenuados contra o sarampo só é contra-indicada para as crianças com comprometimento imunológico grave, ou seja, com contagem de CD4 menor que $15 \%$ do total de linfócitos ${ }^{1,2}$. Entre 1989 e 1991, foram relatados 19 casos fatais de sarampo ocorridos nos Estados Unidos, sendo que 11 deles ocorreram em crianças infectadas pelo HIV. A taxa de mortalidade por sarampo em crianças soropositivas para o HIV chega a $40 \%$ nos hospitais do Zaire².

Até 1996, os estudos disponíveis na literatura não relatavam aumento de efeitos colaterais da vacina contra o sarampo em pacientes infectados pelo HIV ${ }^{3-8}$. A ocorrência de um caso fatal de pneumonite atípica, causada pela cepa vacinal do vírus do sarampo, fez ressurgir a discussão sobre os riscos dessa vacina em soropositivos para o HIV 9 . Em outros estudos, o vírus vacinal não foi recuperado nas culturas de células mononucleares e polimorfonucleares do sangue periférico, nem no plasma dos pacientes infectados pelo HIV e imunizados com a vacina MMR. Esses pacientes também não apresentaram aumento dos níveis de antígeno p24 após a imunização, o que sugere não ter havido estimulação da replicação do HIV em consequiência do uso da vacina ${ }^{10}$.

A resposta imunológica à vacina pode ser incompleta $\mathrm{e}$ menos duradoura, de modo que é recomendado o uso de imunoglobulina específica após a exposição ao sarampo nas crianças com infecção sintomática pelo HIV, mesmo que devidamente imunizadas ${ }^{1,11}$.

A transferência de anticorpos maternos pode estar seriamente prejudicada na presença da infecção pelo HIV. Alguns autores têm sugerido que as crianças nascidas de mães infectadas pelo HIV sejam submetidas também à sorologia para o sarampo o mais breve possível, de modo que, naquelas sem anticorpos maternos, a vacina contra o sarampo possa ser antecipada ${ }^{12}$. Os autores sugerem, ainda, que as crianças com infecção pelo HIV devam ser vacinadas contra o sarampo o mais precocemente possível, devido à pequena duração da imunidade passivamente transmitida pelas mães, e antes que o dano imunológico se instale $^{2,12}$.

O estudo da proteção contra o sarampo conferida pela imunização ativa em crianças infectadas por via perinatal, pelo HIV, reveste-se de maior importância atualmente devido ao ressurgimento do sarampo no Brasil e em outros países do mundo. A imunização rotineira e as campanhas de vacinação em massa fizeram com que as taxas de incidência do sarampo no Brasil caíssem brutalmente, atingindo o nível de 0,05 casos $/ 100.000$ habitantes, em 1995 . No entan- to, desde a campanha de 1992, apenas 32\% dos municípios brasileiros vêm mantendo coberturas satisfatórias para a vacinação de rotina em menores de 1 ano de idade. Somando-se os 5\% dos indivíduos com falha primária da vacinação, o país acumulou cerca de 4 milhões de crianças susceptíveis ao sarampo nos últimos anos, o que foi capaz de promover os surtos ocorridos nos anos de 1996 e 1997. A reversão deste quadro epidemiológico só será possível, segundo o Ministério da Saúde, com a intensificação das campanhas de vacinação em massa, com a manutenção de altas coberturas para a vacinação de rotina e com a identificação de possíveis focos de susceptíveis na comunidade, para os quais estratégias específicas de controle da doença deverão ser propostas ${ }^{13,14}$.

Este estudo foi delineado com o objetivo de verificar a presença de anticorpos contra o sarampo em crianças com infecção perinatal pelo HIV e devidamente vacinadas. O estudo da soroprevalência de anticorpos contra o sarampo poderá ajudar a nortear a elaboração de uma rotina de imunizações mais adequada para crianças soropositivas para o HIV, maximizando suas potencialidades imunológicas, seja através da utilização de novos produtos imunobiológicos, seja por modificação da rotina básica, reduzindo a faixa etária de administração das vacinas, aplicando outras doses de reforço, ou, ainda, evitando que a imunodepressão se instale tão rapidamente.

\section{Métodos \\ Grupos}

Durante o período de agosto de 1995 a agosto de 1996, pacientes pediátricos infectados e não-infectados pelo HIV foram selecionados para compor os dois grupos que fizeram parte desta investigação, totalizando 50 pacientes. $\mathrm{O}$ grupo de crianças infectadas por via perinatal, pelo HIV, foi composto por 21 pacientes acompanhados no Centro de Treinamento e Referência "Orestes Diniz" (CTR). O segundo grupo de pacientes foi composto por 29 crianças em tratamento em diversos ambulatórios do Hospital das Clínicas - UFMG (HC-UFMG) e que preencheram os critérios de inclusão na pesquisa. Esta investigação foi delineada como um estudo prospectivo não-concorrente ou coorte histórica, no qual a imunização contra o sarampo foi o elemento central da formação da coorte, a exposição foi definida pela infecção pelo HIV, e o evento mensurado foi a presença de anticorpos contra o sarampo.

No grupo de crianças infectadas pelo HIV, foram incluídas apenas aquelas com transmissão perinatal do vírus, ou seja, aquelas cujas mães eram sabidamente soropositivas para o HIV ou cujo óbito da mãe deveu-se a patologias sugestivas dessa infecção, e sem relato de qualquer outra fonte possível de transmissão do HIV. Foram consideradas soropositivas as crianças maiores de 15 meses de vida, que apresentaram pelo menos dois resultados do teste de ELISA (Enzyme Linked Immunosorbent Assay) positivos para o HIV, em ocasiões diferentes, e pelo menos 1 resultado 
positivo pela técnica de Western-Blot, testes esses realizados anteriormente a esta pesquisa, durante o acompanhamento ambulatorial de rotina no CTR.

As crianças que compuseram o grupo controle (soronegativos para o HIV) eram pacientes dos diversos ambulatórios de especialidades pediátricas do HC-UFMG, e foram selecionadas pela equipe de pesquisadores no momento em que compareceram ao laboratório central do HC para coleta de sangue. Os critérios para inclusão dos pacientes neste grupo foram: idade maior ou igual a 15 meses; a ausência de patologias, condições ou mesmo medicamentos que pudessem interferir na resposta imunológica do paciente (especialmente anemia, desnutrição, infecções de repetição, neoplasias, uso de corticóides, quimioterápicos e hemotransfusão); resultados dos testes laboratoriais para avaliação da resposta imunológica (hemograma completo, contagem diferencial de linfócitos CD4 e CD8, dosagem sérica de imunoglobulinas e dosagem de $\beta_{2}$-microglobulina) dentro dos limites da normalidade para a idade; sorologia negativa para o HIV e a concordância dos pais ou responsáveis em participar do estudo.

A triagem clínica foi realizada numa entrevista com os pais, no próprio laboratório, e a amostra de sangue foi coletada para os testes acima, além daqueles que motivaram a venopunção, conforme a rotina do serviço. $\mathrm{O}$ estado vacinal dos pacientes foi avaliado pelo cartão de imunizações, através do qual foram obtidos o número de doses de cada vacina e a data da última imunização, sendo a apresentação deste necessária para a inclusão das crianças nos 2 grupos.

Estabeleceu-se, também, como critério de inclusão (em ambos os grupos) que os pacientes deveriam ter recebido duas doses da vacina contra o sarampo ou pelo menos uma dose, administrada após o primeiro ano de vida, embora o Ministério da Saúde - PNI (Programa Nacional de Imunização) considere a segunda dose da vacina contra o sarampo obrigatória para a conclusão do esquema vacinal básico ${ }^{15}$. Para efeito de contagem de número de doses, computou-se as doses da vacina tríplice viral como doses de vacina contra o sarampo. As crianças foram vacinadas como de rotina nos serviços públicos de saúde ou em clínicas particulares, anteriormente a este estudo, e sem qualquer interferência dos pesquisadores.

Nenhuma criança do grupo controle apresentou resultado positivo do teste de ELISA para HIV, e apenas 1 paciente foi excluído por apresentar contagem de CD4 abaixo do esperado para a idade, tendo sido encaminhado ao CTROrestes Diniz para investigação de imunodeficiência.

O consentimento pós-informação, dado pelos pais ou responsáveis, foi condição necessária para a inclusão do paciente no estudo e foi assinado antes da coleta do sangue. O termo de consentimento pós-informação e o protocolo para coleta dos dados foram elaborados especificamente para esta investigação e foram submetidos à apreciação da Câmara do Departamento de Pediatria da Faculdade de
Medicina da UFMG e do Comitê Técnico-Científico do Hospital das Clínicas da UFMG, tendo sido aprovados em ambas as instâncias.

\section{Sorologia para o sarampo}

A amostra de sangue obtida foi centrifugada imediatamente após sua coleta no Laboratório Central do Hospital das Clínicas - UFMG, e o soro, congelado a $-20^{\circ} \mathrm{C}$, de modo que os soros de todos os pacientes foram testados na mesma ocasião. Os técnicos que realizaram os exames no Laboratório de Tecnologia Virológica de Biomanguinhos e no Laboratório de Vírus Respiratórios da FIOCRUZ (RJ) não tiveram acesso à relação de pacientes infectados e nãoinfectados pelo HIV. Os tubos contendo os soros foram identificados apenas pelas iniciais do nome do paciente e o número de ordem de entrada no estudo.

O teste de neutralização por redução de placa foi realizado conforme descrito anteriormente por Whitle et al. $(1984)^{16}$. Amostras com títulos superiores a $50 \mathrm{mUI} / \mathrm{ml}$ foram consideradas positivas. $O$ teste de neutralização por redução de placa é particularmente útil na avaliação da persistência de anticorpos transplacentários e da duração da imunidade de indivíduos vacinados, ou seja, da suscetibilidade ao vírus do sarampo. A presença de IgM específica para o sarampo foi verificada pela técnica de ELISA de captura com anti-IgM humano segundo protocolo padronizado pelo Centers for Disease Control and Prevention $(C D C)$, considerado padrão-ouro para o diagnóstico de infecção recente pelo vírus do sarampo ${ }^{17,18}$.

\section{Análise estatística}

Utilizou-se a análise de variância de Fisher (ANOVA) para a comparação das médias aritméticas ou, quando indicado, métodos não-paramétricos de comparação de medianas (Kruskall-Wallis). O teste de Qui-quadrado foi utilizado na comparação de frequiências. Nas situações em que esse teste não foi considerado adequado, utilizou-se o teste exato de Fisher na análise dos resultados ${ }^{19}$. Esses cálculos foram processados no programa EPI Info, versão 6,04b (CDC/WHO, janeiro/97). A comparação dos títulos de anticorpos para sarampo foi baseada na média geométrica dos valores dos indivíduos cujo título estivesse dentro dos limites de detecção do método laboratorial utilizado. O teste t-student foi utilizado para a comparação dos títulos geométricos médios (GMT). Adotou-se o nível de significância de 5\% em todas as análises estatísticas realizadas. O cálculo do tamanho do grupo de crianças não-infectadas foi feito de modo a garantir poder estatístico de pelo menos $80 \%$ quando os títulos de anticorpos contra o sarampo dos grupos fossem comparados, esperando-se um risco relativo menor que 0,5 , ou seja, supondo-se que a taxa de soroprevalência de anticorpos contra o sarampo entre os infectados seria cerca de $50 \%$ menor do que a taxa esperada para os não-infectados. 


\section{Resultados}

\section{Características gerais dos grupos}

As manifestações da infecção pelo HIV foram classificadas como leves ou moderadas em aproximadamente $73 \%$ dos pacientes, segundo os critérios de classificação da infecção pelo HIV em menores de $13 \operatorname{anos}^{20}$. No entanto, ao considerarmos apenas o nível de imunossupressão, medido pela contagem relativa de linfócitos CD4, vimos que 90,9\% das crianças apresentaram imunossupressão moderada ou grave (categorias 2 e 3 da classificação acima). O uso de drogas antiretrovirais (AZT ou DDI) foi observado em $54,5 \%$ dos pacientes no momento da coleta do sangue para a sorologia. Apenas $27,3 \%$ dos pacientes estavam em uso de imunoglobulina endovenosa (IVIG), simultaneamente ou não, com o uso de drogas antiretrovirais. A coleta do sangue foi feita com intervalo mínimo de 3 semanas após a administração de IVIG nesses pacientes. A Tabela 1 demonstra a distribuição dos 21 pacientes infectados em relação à classificação clínico-laboratorial, ao uso de drogas antiretrovirais, IVIG e ao título de anticorpos contra o sarampo. O pequeno número de pacientes nessas categorias tornou os resultados inconclusivos (poder estatístico menor que $40 \%$ ).

A idade das crianças soropositivas para o HIV variou de 15 meses a 10 anos, e das crianças do grupo controle, de 19 meses a 13 anos. A Tabela 2 demonstra que a mediana de idade do grupo de pacientes infectados pelo HIV foi 44,5 meses, e a do grupo não-infectado, 62,0 meses, $\mathrm{p}=0,64$ (Kruskal-Wallis), sendo a diferença desprovida de significado estatístico.

Tabela 1 - Distribuição dos pacientes infectados pelo HIV, segundo título protetor de anticorpos contra o sarampo, classificação clínico-laboratorial, uso de drogas anti-retrovirais e imunoglobulina endovenosa

\begin{tabular}{|c|c|c|c|}
\hline & \multicolumn{2}{|c|}{$\begin{array}{c}\text { Título protetor } \\
\quad(\mathbf{n = 2 1})\end{array}$} & \multirow[b]{2}{*}{$\mathbf{p}$} \\
\hline & Sim & Não & \\
\hline \multicolumn{4}{|c|}{ Classificação CDC/94 } \\
\hline A $(1,2$ e 3$)$ & 2 & 3 & \\
\hline $\mathrm{B}(1,2$ e 3$)$ & 5 & 5 & * \\
\hline $\mathrm{C}(2$ e 3$)$ & 5 & 1 & \\
\hline \multicolumn{4}{|c|}{ Drogas Anti-retrovirais } \\
\hline AZT/ DDI & 6 & 5 & $1,00^{\dagger}$ \\
\hline Não usam & 6 & 4 & \\
\hline \multicolumn{4}{|l|}{ IVIG } \\
\hline Sim & 3 & 2 & $1,00^{\dagger}$ \\
\hline Não & 9 & 7 & \\
\hline
\end{tabular}

Tabela 2 - Distribuição de 50 pacientes, segundo infecção pelo HIV, idade, número de doses e intervalo desde a última dose de vacina contra o sarampo e título de anticorpos contra o sarampo

\begin{tabular}{|c|c|c|c|}
\hline Características & $\begin{array}{c}\text { Infectados } \\
(\mathbf{n}=21)\end{array}$ & $\begin{array}{c}\text { Não-infectados } \\
\quad(\mathbf{n}=29)\end{array}$ & $\mathbf{p}$ \\
\hline \multicolumn{4}{|l|}{ Idade (meses) } \\
\hline Média+desvio-padrão & $57,6 \pm 30,5$ & $64,6 \pm 36,1$ & \\
\hline Mediana & $4 \overline{4}, 5$ & $6 \overline{2}, 0$ & $0,64 \S$ \\
\hline \multicolumn{4}{|l|}{ Intervalo em meses* } \\
\hline Média \pm desvio-padrão & $29,4 \pm 31,9$ & $25,2 \pm 18,3$ & \\
\hline Mediana & $1 \overline{7}, 0$ & $1 \overline{6}, 0$ & $0,98 \S$ \\
\hline \multicolumn{4}{|l|}{ Número de doses } \\
\hline Média \pm desvio-padrão & $1,9 \pm 0,7$ & $2,3 \pm 0,7$ & \\
\hline Mediana & 2,0 & 2,0 & $0,062 \S$ \\
\hline $\begin{array}{l}\text { GMT de anticorpos }{ }^{\dagger} \\
(\mathrm{mUI} / \mathrm{ml})\end{array}$ & $\begin{array}{l}433,5 \\
(n=12)\end{array}$ & $\begin{array}{l}1668,1^{\mathbb{I}} \\
(\mathrm{n}=24)\end{array}$ & $0,001^{\ddagger}$ \\
\hline
\end{tabular}

* Tempo, em meses, decorrido entre a última dose da vacina contra o sarampo e a coleta do sangue para sorologia

† Título geométrico médio dos pacientes com título de anticorpos neutralizantes entre 50 e $6309,5 \mathrm{mUI} / \mathrm{ml}$

§ Kruskal-Wallis

II Excluídos 5 pacientes com títulos $>6309,5 \mathrm{mUl} / \mathrm{ml}$

‡ Teste t-student

Os pacientes não-infectados pelo HIV foram provenientes de diversas especialidades pediátricas do Ambulatório Bias Fortes (HC-UFMG). O motivo da coleta de sangue foi a realização de exames pré-operatórios para cirurgias eletivas em $51,61 \%$ dos casos.

\section{Sorologia para o sarampo}

A mediana do número de doses e do intervalo decorrido desde a última dose da vacina contra o sarampo foram estatisticamente semelhantes entre os grupos $(\mathrm{p}=0,062$ e $\mathrm{p}=0,98$, respectivamente), como demonstra a Tabela 2. Os grupos continuaram estatisticamente semelhantes quando os pacientes foram estratificados segundo as categorias "doses" e "intervalos" ( $\mathrm{p}=0,12 \mathrm{e} \mathrm{p}=0,49$, respectivamente). Uma criança não-infectada e 5 infectadas pelo HIV receberam apenas 1 dose dessa vacina, porém todas estavam com mais de 1 ano por ocasião da imunização contra o sarampo.

O GMT (Tabela 2) de anticorpos contra o sarampo foi significativamente maior no grupo de pacientes não-infectados $(\mathrm{p}=0,001)$. Foram incluídas no cálculo do GMT apenas as crianças cujos títulos encontrados estavam dentro dos limites de detecção do método (50-6309,5 mUI/ml). Na Figura 1, estão distribuídos os 50 pacientes segundo o título de anticorpos contra o sarampo e a infecção pelo HIV. Nota-se que cerca de $90 \%$ dos pacientes infectados pelo HIV têm títulos de anticorpos menores que 1000 mUI/ml, enquanto os pacientes não-infectados distribuem-se hetero- 


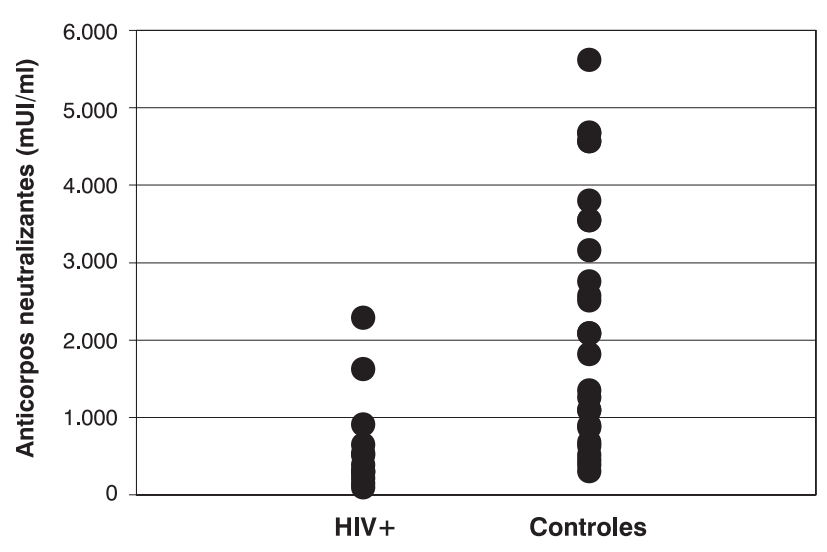

Gráfico 1 - Distribuição dos pacientes infectados e não-infectados pelo HIV, segundo título de anticorpos neutralizantes contra o sarampo

geneamente, tendendo a concentrar-se em valores mais altos do teste.

A Tabela 3 demonstra a distribuição dos pacientes segundo o título de anticorpos, número de doses e intervalo decorrido desde a última dose da vacina contra o sarampo. Dos 21 pacientes infectados pelo HIV, 9 (42,9\%) apresentaram títulos de anticorpos neutralizantes menores que 50 $\mathrm{mUI} / \mathrm{ml}$, enquanto todas as crianças não-infectadas tinham títulos de anticorpos acima desse nível (risco relativo = 0,57; IC: 0,39-0,83).

Tabela 3 - Distribuição de 50 pacientes, segundo título de anticorpos contra o sarampo, infecção pelo HIV, número de doses e intervalo desde a última dose da vacina contra o sarampo

\begin{tabular}{|c|c|c|c|}
\hline & \multicolumn{2}{|c|}{$\begin{array}{c}\text { Título de anticorpos } \\
\text { contra o sarampo }\end{array}$} & \multirow[b]{2}{*}{$\mathbf{p}$} \\
\hline & $\geq 50 \mathrm{mUI} / \mathrm{ml}$ & $<50 \mathrm{mUI} / \mathrm{ml}$ & \\
\hline Infectados $(\mathrm{n}=21)$ & 12 & 9 & $0,0001 *$ \\
\hline Não-infectados $(n=29)$ & 29 & 0 & \\
\hline \multicolumn{4}{|l|}{ Número de doses } \\
\hline Média+desvio-padrão & $2,2 \pm 0,7$ & $1,9 \pm 0,8$ & \\
\hline Mediana & 2,0 & 2,0 & $0,19^{\dagger}$ \\
\hline \multicolumn{4}{|l|}{ Intervalo em meses } \\
\hline Média \pm desvio-padrão & $26,3 \pm 25,4$ & $29,9 \pm 22,8$ & \\
\hline Mediana & $1 \overline{6}, 0$ & $1 \overline{7}, 0$ & $0,45^{\dagger}$ \\
\hline
\end{tabular}

A estratificação dos pacientes segundo o título de anticorpos contra o sarampo, de acordo com as categorias "doses" e "intervalo" também não revelou significância estatística ( $p=0,16$ e $p=0,89$, respectivamente). As médias de idade foram estatisticamente semelhantes quando as crianças foram agrupadas segundo o título de anticorpos ( $\mathrm{p}=0,55$; Kruskall-Wallis). Nenhuma das crianças, entre infectadas e não-infectadas, apresentou reatividade aos testes de ELISA para IgM contra o sarampo, sendo consideradas soronegativas para esta imunoglobulina.

\section{Discussão}

Esta investigação foi delineada como um estudo de coorte retrospectivo ou histórico, no qual a variável central (vacinação) não esteve sob controle dos pesquisadores. Assim, os pacientes infectados por via perinatal, em acompanhamento pediátrico no CTR-Orestes Diniz, foram identificados pela equipe de pesquisadores, mas apenas aqueles possuidores de cartão de imunizações foram incluídos no estudo, considerando ser este o único registro confiável da história vacinal dos pacientes. Por motivos operacionais, tornou-se impossível acompanhar prospectivamente uma coorte de pacientes desde o nascimento, para que as imunizações fossem devidamente indicadas, administradas e registradas pela própria equipe de pesquisadores.

Todas as crianças não-infectadas pelo HIV apresentaram títulos de anticorpos acima de $50 \mathrm{mUI} / \mathrm{ml}$, limite inferior de detecção do método, enquanto $12(57,1 \%)$ das 21 crianças apresentaram títulos acima desse valor. O título de anticorpos neutralizantes contra o sarampo não foi influenciado pelo número de doses e nem pelo intervalo decorrido desde a última dose da vacina contra o sarampo e a coleta do sangue, como mostram os resultados apresentados nas Tabelas 2 e 3 . A taxa de pacientes considerados soropositivos para o sarampo, observada neste estudo, foi comparável àquelas encontradas na literatura, que variou de 50 a 59,4\% nos estudos cuja metodologia aproximou-se da utilizada nesta investigação $8,11,21,22$.

Embora a presença de qualquer título detectável de anticorpos contra o sarampo possa ser considerado protetor, dados disponíveis na literatura sugerem que algumas pessoas com títulos de anticorpos muito baixos podem não estar completamente protegidas. Sarampo propriamente dito ou a doença sem exantema podem ocorrer em indivíduos com títulos de anticorpos neutralizantes menores que $120 \mathrm{mUI} / \mathrm{ml}^{23}$.

Peter (1991) ${ }^{24}$, em artigo de revisão, descreve que 5\% ou menos das crianças adequadamente imunizadas falham em responder à vacinação contra o sarampo. Segundo Krugman $(1983)^{25}$, cerca de $15 \%$ das crianças devidamente imunizadas podem apresentar níveis indetectáveis de anticorpos e ainda assim desencadear resposta anamnéstica rápida quando novamente expostas ao vírus do sarampo. Por outro lado, Markowitz et al. (1990) ${ }^{26}$ relatam a existência de falha secundária na resposta à vacina contra o 
sarampo, representada pela perda de anticorpos após soroconversão, cuja magnitude e importância epidemiológica ainda carecem de estudos mais aprofundados. Mesmo considerando esses aspectos, o índice de crianças infectadas pelo HIV com títulos acima de $50 \mathrm{mUI} / \mathrm{ml}$ foi significativamente inferior ao do grupo de não-infectadas, o que certamente não representa apenas falha primária ou secundária ou queda do título de anticorpos, mas sim a atuação do HIV nos diversos mecanismos da resposta imune.

No presente estudo, o título geométrico médio (GMT) dos pacientes com mais de $50 \mathrm{mUI} / \mathrm{ml}$ de anticorpos neutralizantes contra o sarampo também foi significativamente menor nas crianças soropositivas para o HIV $(433,5 \mathrm{x}$ $1668,1 \mathrm{mUI} / \mathrm{ml}$ ), o que pode ser atribuído à menor produção de anticorpos em resposta à vacina, ou à perda mais acelerada dos anticorpos produzidos, ou ambos os mecanismos. Resultado semelhante é descrito na literatura, mas o mecanismo imunológico de base também não pôde ser esclarecido $^{27}$.

A baixa prevalência de anticorpos contra o sarampo nas crianças soropositivas para o HIV reforça a preocupação em relação a surtos de sarampo em grupos de pessoas susceptíveis devido a falha primária ou secundária da imunização, quando, mesmo imunizadas, as pessoas são capazes de transmitir o vírus selvagem ${ }^{24,26}$. Tais situações poderão comprometer as tentativas de eliminação do sarampo, devido à alta transmissibilidade do vírus selvagem, ainda que o número de pessoas susceptíveis seja relativamente pequeno.

Concluímos que, apesar de devidamente imunizadas contra o sarampo, as crianças com infecção perinatal pelo HIV apresentam menor prevalência de anticorpos contra o sarampo, e menor magnitude da resposta imunológica, quando comparadas com crianças de grupos etários semelhantes e sem comprometimento imunológico.

Os resultados encontrados apontam a necessidade de melhor monitoramento das crianças infectadas pelo HIV, por via perinatal, frente ao risco de adquirir o sarampo. Abordagens especiais poderão envolver alterações no calendário vacinal, como a antecipação da primeira dose da vacina contra o sarampo e/ou introdução de novas doses de reforço, utilização de produtos mais imunogênicos e, em última análise, prevenção da transmissão perinatal do HIV e redução do dano imunológico através do uso sistemático de antiretrovirais na gravidez, parto e período neonatal.

\section{Agradecimentos}

Os autores agradecem ao Dr. W.J. Bellini, da divisão de sarampo do CDC/Atlanta, por fornecer gentilmente os reagentes para o teste de ELISA-CDC; ao Dr. Marcos S. Freire e Anna M. Yamamura, do Laboratório de Tecnologia Virológica, Biomanguinhos/FIOCRUZ-RJ, pelo suporte técnico para a realização do PRNT, e ao Centro de Pesquisas René Rachou/ FIOCRUZ-MG, pelo apoio financeiro e logístico indispensável à realização deste estudo.

\section{Referências bibliográficas}

1. Centers for Disease Control and Prevention - CDC. Measles, Mumps and Rubella - Vaccine use and strategies for elimination of measles, rubella and rubella syndrome and control of mumps: recommendations of the Advisory Committee on Immunization Practices (ACIP). MMWR 1998; 47, RR08:1-57.

2. Arpadi SM. Current recommendations for vaccinating HIVinfected children. Infect Med 1997;729,14:720-4.

3. Krasinski K, Borkowsky W. Measles and measles immunity in children infected with human immunodeficiency virus. JAMA 1989;261,17:2512-16.

4. Palumbo P, Hoyt L, Demasio K, Oleske J, Connor E. Populationbased study of measles immunization in human immunodeficiency virus-infected children. Pediatr Infect Dis J 1992; 11,12:1008-42.

5. Mclaughlin M, Thomas P, Onorato I, Rubinstein A, Oleske J, Nicholas $\mathrm{S}$, et al. Live virus vaccines in human immunodeficiency virus-infected children: a retrospective survey. Pediatrics 1988; 82, 2: 229-33.

6. Lepage P, Dabis F, Msellati P, Hitimana DG, Stevens A-M, Mukamabano B, et al. Safety and immunogenicity of high-dose Edmonston-Zagreb measles vaccine in children with HIV-1 infection; a cohort study in Kigali, Rwanda. Am J Dis Child 1992;146,5:550-5

7. Cutts FT, Mandala K, Louis MS, Brown C, Mayala B, Zell ER, et al. Immunogenicity of high-titer Edmonston-Zagreb measles vaccine in human immunodeficiency virus-infected children in Kinshasa, Zaire. J Infect Dis 1993; 167, 6:1418-21.

8. Rudy BJ, Rutstein RM, Pinto-Martin J. Responses to measles immunization in children infected with human immunodeficiency virus. J Pediatr 1994; 125, 1: 72-74.

9. Centers for Disease Control and Prevention - CDC. Measles pneumonitis following Measles-Mumps-Rubella vaccination of a patient with HIV infection. MMWR 1996;45,28:603-6.

10. Frenkel LM, Nielsen K, Garakian A, Cherry J. A search for persistent measles, mumps, and rubella vaccine virus in children with human immunodeficiency virus type 1 infection. Arch Pediatr Adolesc Med 1994;148, 1: 57-60.

11. Markowitz LE, Orenstein WA. Measles vaccines. Pediatr Clin North Am 1990; 37, 3: 603-25.

12. Moraes-Pinto MI, Farhat CK, Carbonare SB, Curti SP, Otsubo MES, Lazarotti DS, et al. Maternally acquired immunity in newborns from women infected by the human immunodeficiency virus. Acta Paediatr 1993; 82: 1034-8.

13. Brasil. Ministério da Saúde. Fundação Nacional de Saúde. Programa Nacional de Imunizações-20 anos. Brasília: Ministério da Saúde; 1993a.

14. Brasil. Ministério da Saúde. Fundação Nacional de Saúde. Programa de Imunizações. Estratégias recomendadas para o controle do sarampo, Brasil, 1997. Brasília: Ministério da Saúde; 1997.

15. Brasil. Ministério da Saúde. Fundação Nacional de Saúde. Programa de Imunizações. Manual de procedimentos para a vacinação. Brasília: Ministério da Saúde; 1993b.

16. Whittle HC, Rowland MGM, Mann GF, Lamb WH, Lewis RA. Immunization of 4-6 months old Gambian infants with Edmonston-Zagreb measles vaccine. Lancet 1984; 2, 8407: 834-7.

17. Erdman DD, Anderson LJ, Adams DR, Stewart JA, Markowitz LE, Bellini WJ. Evaluation of monoclonal antibody-based capture enzyme immunoassays for detection of specific antibodies to measles virus. J Clin Microbiol 1991;29,7:1466-71.

18. Hummel KB, Erdman DD, Heath J, Bellini WJ. Baculovirus expression of the nucleoprotein gene of measles virus and utility of the recombinant protein in diagnostic enzyme immunoassays. J Clin Microbiol 1992;30:2874-80. 
19. Zar JH. Biostatistical analysis. $2^{\mathrm{a}}$ ed. Prentice Hall; 1984.

20. Centers for Disease Control and Prevention - CDC. 1994 revised classification system for human immunodeficiency virus infection in children less than 13 years of age. MMWR 1994; 43, RR12:1-10.

21. Brena AE, Cooper ER, Cabral HJ, Pelton SI. Antibody response to measles and rubella vaccine by children with HIV infection. J Acquir Immune Defic Syndr 1993;6,10: 1125-9.

22. Arpadi SM, Markowitz LE, Baughman AL, Shah K, Adam H, Wiznia A, et al. Measles antibody in vaccinated human immunodeficiency virus type 1 - infected children. Pediatrics 1996; 97 , 5: 653-7.

23. Markowitz LE, Katz SL. Measles vaccine. In: Plotkin SA, Mortiner Jr. EA. Vaccines. $2^{\mathrm{a}}$ ed. Philadelphia: WB Saunders; 1994.p.229-76.

24. Peter G. Measles immunization: recommendations, challenges, and more information. JAMA 1991;265,16: 2111-2.

25. Krugman S. Further-attenuated measles vaccine: characteristics and use. Rev Infect1 Dis 1983;5, 3: 477-81.
26. Markowitz LE, Preblud SR, Fine PE, Orenstein W. Duration of live measles vaccine-induced immunity. Pediatr Infect Dis J 1990; 9,2: 101-10.

27. Al-Attar I, Reisman J, Muehlmann M, McIntosh K. Decline of measles antibody titers after immunization in human immunodeficiency virus-infected children. Pediatr Infect Dis J 1995;4, 2: 149-51.

Endereço para correspondência:

Dra. Claudia Regina Lindgren Alves

Rua Tavares Bastos, 287

CEP 30380-040 - Belo Horizonte, MG

Fones: 313297.5684 / 319985.1611

E-mail:lindgren@medicina.ufmg.br 